\title{
Eidorfe Moreira e o conhecimento transdisciplinar
}

\section{Eidorfe Moreira and transdisciplinary knowledge}

Geraldo Mártires Coelho - Pós-Doutorado em História Cultural e das Mentalidades pela Universidade Nova de Lisboa (1995). Professor Aposentado da Universidade Federal do Pará, Faculdade de História. E-mail: gmartirescoelho@gmail.com

\begin{abstract}
Resumo
A produção intelectual de Eidorfe Moreira marcou-se pela construção de uma obra fundada em uma clara relação epistemológica inter e transdisciplinar do seu objeto, sem dúvida um avanço teórico para o tempo da sua construção. Geografia Cultural, História, Filosofia, Literatura, Sociologia, Geografia Física, Ciência Política, Pedagogia e Estética são alguns dos domínios do conhecimento com os quais Eidorfe Moreira interagiu. $O$ pensamento social fundado nesse denso processo epistemológico revelouse na condição de uma obra que seu autor arguiu domínios distintos do saber, para construir um outro saber, reflexivo de uma epistemologia complexa, na trama de sua fundamentação.
\end{abstract}

\section{Palavras-chave}

Narrativa Interdisciplinar e Transdisciplinar. Geografia Cultural. História Cultural. Complexidade da análise.

\begin{abstract}
The intellectual production of Eidorfe Moreira was marked by the construction of a work founded in a clear epistemological inter and transdisciplinarity relation with the object, without a doubt a theoretic advance in its time of construction. Cultural Geography, History, Philosophy, Physics Geography, Political Science, Education and Aesthetics are some of the domains with Eidorfe Moreira interact. The social thinking established in this deep epistemological process, reveled the condition of a work in which the author debate with distinct areas of knowledge to construct another kind of meaning, reflexive of a complex epistemology build in its substantiation.
\end{abstract}

\section{Keywords}

Interdisciplinar and Transdisciplinar Narrative. Cultural Geography. Cultural History. Complexity of Analysis. 


\section{INTRODUÇÃO}

Em Eidorfe Moreira - Nota Crítica, escrita por Benedito Nunes (1989, p. 25) no $1^{\circ}$ volume da edição que reuniu praticamente a totalidade dos trabalhos do autor de Ideias para uma concepção geográfica da vida (1960), o grande filósofo paraense, assinalando que a sua preocupação não era sistematizadora ou classificatória, agrupou, grosso modo, os trabalhos de Eidorfe Moreira, segundo três grandes identidades epistemológicas: os voltados para a Amazônia, a exemplo de Amazônia; o conceito e a paisagem (1958) e Belém e sua expressão geográfica (1966); os "geográficos-literários, como Presença do mar na literatura brasileira (1962), e, por último, os relacionados à "história cultural do Pará", caso de Visão geossocial do Círio (1971) e Presença hebraica no Pará (1972), aos quais incluiríamos Os sermões que Vieira pregou no Pará (1970).

É possível distender o entendimento de "história cultural do Pará" pensado por Benedito Nunes e incluir Obras escolares paraenses de história (1977) e O livro didático paraense (1979), os títulos voltados ao ensino médio no Pará, como também o fez com o ensino superior ao escrever sobre As letras jurídicas no Pará (1973) e Para a história da Universidade Federal do Pará (1977). Como bem reconheceu Benedito Nunes (1989, p. 25), para além de uma preocupação meramente classificatória, essa divisão realça a diversidade dos estudos produzidos por Eidorfe Moreira "dentro do domínio das ciências humanas, e destaca a escala científico-humanista de seus temas".

Nesse sentido, a obra de Eidorfe Moreira, usando uma imagem da astrofísica, remete para a representação de um universo em expansão, transgressor de formalismos, transgressor de limites. Só assim é possível ao autor escrever, reunir e publicar Estado e Ideologia e Política e Aretologia (a virtude como princípio político em Platão e Aristóteles) (1959) e, depois, D. Quixote e o problema do conhecimento (1968), neste caso propondo-se a uma "análise epistemológica do herói cervantino". Esse Eidorfe Moreira, criador, é o mesmo que, em 1969, publicava um Roteiro bibliográfico de Marajó. As obras, formalmente observadas, são discursos distintos, mas a sua unidade estava construída na mente do autor, na forma como ele entendia ser a identidade do conhecimento, revelada no campo da relação entre sociedade e cultura, entre o homem, o ambiente e o conhecimento. Assim, mesmo que de forma incompleta, impõe-se, do ponto de vista da arqueologia do saber, recuperar o principal da história e da historicidade do universo intelectual esculpido por Eidorfe Moreira.

$\mathrm{Na}$ passagem da primeira para a segunda metade do século XX, os quadros intelectuais dominantes em Belém apresentavam genética diferenciada. 
Alguns dos seus integrantes provinham da tradição afrancesada e autodidata da belle époque da borracha e da sua cultura mundializada; outros, já procediam dos bancos acadêmicos formais, principalmente da Faculdade de Direito, centro historicamente dominante na formação de quadros brasileiros especializados, inclusive para o exercício do ensino superior. A exemplo do que antes se verificava em outros centros brasileiros, no final dos anos de 1950, aquando da constituição da Faculdade de Filosofia, Ciências e Letras do Pará, muitos dos responsáveis pelas cadeiras dos cursos de História e de Geografia haviam saído da Faculdade de Direito.

Se um ponto de encontro houve entre essas duas admitidas correntes de homens de letras da Belém de então, foi a contingência de praticamente todos eles servirem à administração pública, à gestão do Estado. Eidorfe Moreira foi um intelectual refinado. Representava, nesse sentido, o perfil letrado dos bomens de letras, dotado de uma saber construído em múltiplas frentes do conhecimento. Em outras palavras, trabalhando-se a bibliografia deixada por Eidorfe Moreira, sobressai de forma clara a pluralidade de leituras que realizou e de estudos que buscou. O escritor, é possível sustentar, criou uma identidade própria, tratandose da vida intelectual da Belém do seu tempo (CHAVES, 1989, P. 18-19). É preciso visitar alguns dos suportes que sustentaram o intelectual à frente do seu tempo que foi Eidorfe Moreira.

A produção intelectual de Eidorfe Moreira, anunciada, por assim dizer, ao findar a década de 1950, reuniria títulos que permitem recuperar o percurso de sua formação intelectual, de sólida erudição histórico-filosófica - transcendendo, é claro, a sua matriz geográfica. A geografia de Eidorfe Moreira, para além do conceito estrito da problemática do espaço, sempre seria pensada em relação direta com os domínios contidos no campo significante de cultura. História, filosofia, antropologia, sociologia e literatura, por exemplo, compõem o universo discursivo de Eidorfe Moreira, aproximando-o, como a seguir será melhor trabalhado, dos modelos teórico-metodológicos que haviam revolucionado as ciências humanas na França, que vivia o começo do século XX.

Em 1958, o aparecimento de Amazônia: o conceito e a paisagem, anunciava o ensaísta que trabalhava de forma interdisciplinar, e para quem a geografia, a paisagem e o homem constituíam um universo a ser pensado e arguido em sua unívoca dimensão espacial, social e cultural. Um ano depois, em 1959, surgia, seguindo a mesma linha de identidade ensaística, o estudo Sertão: a palavra e a imagem. A identidade epistemológica construída por Eidorfe Moreira já nos seus primeiros trabalhos transcendia, por assim dizer, ao trato marcantemente geográfico conferido ao objeto de seus estudos. 
O ensaísta distendia, assim, o arco de suas leituras, de suas reflexões, interagindo e dialogando com a história, a filosofia, a literatura, as artes. Em outras palavras, desde os seus estudos iniciais, Eidorfe Moreira revelava uma formação humanística elástica, em permanente processo de solidificação, que o acompanharia em todo o exemplar processo de sua história intelectual. A construção dessa identidade epistemológica, repita-se, Eidorfe Moreira a fez do ponto de vista de um geógrafo, sim, mas no interior de um pensamento em que a geografia era considerada na relação entre espaço, tempo e cultura.

Uma peregrinação pela bibliografia trabalhada em Amazônia: o conceito e a paisagem e também em Sertão: a palavra e a imagem revela que Eidorfe Moreira já dominava, no final dos anos de 1950, um universo bibliográfico bem expressivo. Esse capital simbólico lhe permitiu um tratamento e uma leitura interdisciplinares dos cenários buscados por sua arguição, construindo uma abordagem em que os quadros geográficos são culturalmente pensados e problematizados. Assim, quer em Amazônia: o conceito e a paisagem, como em Sertão: a palavra e a imagem, o suporte epistemológico das obras fez com que em ambos os títulos encontremse referências à literatura de Euclides da Cunha, Guimarães Rosa e Vianna Moog; à história de Capistrano de Abreu, Visconde de Taunay, Henri Berr, Araújo Lima e Arthur Cézar Ferreira Reis; à geografia de Emmanuel De Mortonne, Pierre Deffontaines e Pierre Gourou; à literatura de interesse antropológico e geográfico dos viajantes Spix, Martius, Henry Bates, Alfred Wallace e Louis Agassiz.

Observem-se, ainda, as referências do ensaísta a nomes como Vidal de la Blache, geógrafo francês que, no início do século XX, esteve próximo de historiadores e sociólogos, e que em 1891 fundou os Annales de Geographie. Foi o que se deu em relação a Lucien Febvre, um dos deflagradores do movimento dos Annales no começo do século XX, em que a relação interdisciplinar passou a sustentar a nova história feita então na França. Não sem razão, a revista Annales d'histoire économique et sociale, surgida em 1929, sob a liderança de Marc Bloch e Lucien Febvre, teve como modelo os Annales de Géographie de La Blache, contando em seu conselho editorial com a presença do geógrafo Albert Demangeon. Fica evidente, em outras palavras, que Eidorfe Moreira, ao final dos anos de 1950, estava a par do que, àquela altura, já manifestava na França uma nova relação entre história e geografia no quadro epistemológico das ciências humanas.

Dois outros grandes trabalhos foram dados à estampa por Eidorfe Moreira nesse mesmo período, mais exatamente em 1960 e 1962, respectivamente: Ideias para uma concepção geográfica da vida e Presença do mar na literatura brasileira, ambos objeto de uma leitura mais detalhada em parte posterior deste trabalho, 
justamente para que se evidencie o trato inter e transdisciplinar empregado por Eidorfe Moreira na construção de sua narrativa. Ainda que as referências aqui feitas digam respeito aos trabalhos iniciais de Eidorfe Moreira, seguindo-se à linha do aparecimento dos mesmos, fica manifestada a preocupação de não apenas identificar as obras, mas já salientar, mesmo que em linhas gerais, os compostos teórico-metodológicos que fundam a sua engenharia discursiva.

Ainda em 1966, seguindo essa mesma linha de construção epistemológica, surgiu o estudo Belém e sua expressão geográfica. Por isso mesmo, neste ensaio seu autor funda a sua leitura no solo fértil da narrativa histórica, recorrendo, para tanto, a historiadores brasileiros como Sérgio Buarque de Holanda e João Lúcio de Azevedo, a historiadores franceses, a exemplo de Fustel de Coulanges e Lucien Romier, ao português Oliveira Martins, além de Domingos Antônio Raiol, Manuel Barata e Bernardo Pereira de Berredo. Nos domínios da geografia, o estudo recorre aos geógrafos franceses Pierre George, Auguste Plane e Pierre Monbeig, uma geografia também pensada em termos de sua utilização na narrativa literária de José Lins do Rego e Leandro Tocantins.

Como o olhar de Eidorfe Moreira para a expressão geográfica de Belém está fundado, repita-se, sobre uma perspectiva histórica, o quadro que pinta dos cenários físicos e culturais em que a cidade surgiu e foi se afirmando, historicamente falando. Vale-se o escritor também de registros feitos por viajantes que passaram pela Amazônia nos séculos XVIII e XIX, um procedimento que é essencial à sua narrativa. Assim, o ensaísta recepcionou em seu estudo La Condamine, Spix, Martius, Hercule Florence e Paul Le Cointe, sabidamente responsáveis por uma leitura dita naturalista da Amazônia cientificamente falando. A relação cultural de Eidorfe Moreira com a geografia revelou-se, ainda, por meio de Visão geossocial do Círio e Kant como geógrafo, de 1971 e 1972, o último depois integrado em Geografias mágicas, de 1989, obra esta com que Eidorfe Moreira fechou a sua fecunda bibliografia.

Uma visita às temáticas que Eidorfe Moreira trabalhou e reuniu em Geografias mágicas, como em Dom Quixote e o problema do conhecimento, de 1968, além do acima citado Kant como geógrafo ou ainda O nefelismo de El Greco, de 1972, passando também por Os Lusíadas em termos geográficos, A Amazônia de Júlio Verne e Jesus visto pelo geógrafo, essa visita deixa claro que Eidorfe Moreira trabalhou segundo uma perspectiva teórica e metodológica do conhecimento transdisciplinar. Filosofia, história, literatura, arte, como melhor será visto a seguir, fundaram os alicerces da geografia cultural de Eidorfe Moreira, revelação de um objeto epistemológico estranho às formas conhecidas e reconhecidas de pensar a relação entre a geografia e outros domínios das ciências humanas, então dominantes no Brasil. 
Dito de outro modo, e esse é o fim buscado na exposição ora em andamento, como a geografia cultural no Brasil será fruto epistemológico do início dos anos de 1990, o tratamento conferido por Eidorfe Moreira a questões que se identificam como Simbologia dos pântanos, Estética de um apocalipse ou Paráfrase geográfica à selva dantesca, ainda tratando-se de Geografias mágicas, não era exatamente a forma de conhecimento que o saber geográfico de então privilegiava em suas pautas. Nesse sentido, sustenta-se que a densa formação intelectual de Eidorfe Moreira permitiu ao escritor pensar a relação entre o meio e a cultura social por caminhos iluminados por uma epistemologia heterodoxa.

Essa rápida e incompleta incursão pela obra de Eidorfe Moreira tem um objetivo instrumental: assinalar a pluralidade de temáticas trabalhadas pelo ensaísta, deixando evidente, mesmo en passant, que esses trabalhos abrigaram uma relação epistemológica inter e transdisciplinar. O que está em jogo, portanto, não é a diversidade formal das questões estudadas por Eidorfe Moreira, mas, antes, os procedimentos teóricos que adotou na construção da sua narrativa. E como o ensaísta revelar-se-ia como um seguidor da geografia cultural, cujo corpus discursivo abre-se para a história, a filosofia, a sociologia, a estética, as obras de Eidorfe Moreira abrigam a complexidade epistemológica própria dos saberes compósitos. Observando-se o conjunto da obra de Eidorfe Moreira, fica evidente, tratando-se dos corpos da geografia cultural, que o ensaísta manteve-se sempre muito próximo das matrizes intelectuais das ciências sociais da França, na passagem da primeira para a segunda metade do século XX.

O fruto primeiro dessa investida de Eidorfe Moreira pelas matrizes da geografia e da história francesa chamadas dos Annales, viria cedo, na forma de um dos mais arrojados e provocantes ensaios, pelo surto de suas proposições. Em 1960, o autor daria à estampa Ideias para uma concepção geográfica da vida, obra que amplia a originalidade do pensamento de Eidorfe Moreira, já delineada em seus primeiros trabalhos. Considerando os múltiplos sentidos de que se reveste Ideias para uma concepção geográfica da vida, este trabalho requer, agora, espaços da reflexão proposta no título deste trabalho, buscando-se no corpus do ensaio a confluência das leituras, das questões e das problematizações levantadas e trabalhadas por Eidorfe Moreira. O próprio título da obra implica como que um projeto, um programa, uma teorização acerca de uma condução do viver em sintonia com o meio, o ambiente - o ecossitema, seria o conceito de hoje. Assim, é preciso considerar, inicialmente, que o título emprestado por Eidorfe Moreira em seu 
trabalho remete para domínios epistemológicos, filosóficos, históricos - todos, de alguma forma, integrando o campo significante da cultura. A relação, portanto, entre o homem e o meio, entre a criatura e o seu habitat, vai além do meramente físico, espacial, morfológico, para se inscrever na saga da própria humanidade pela polis planetária que fundou a condição humana.

Registre-se, nesse sentido, que, em Ideias para uma concep̧̧ão geográfica da vida, de 1960, Eidorfe Moreira faz referência a Henri Berr e a sua Revue de Synthése Historique, um dos títulos identitários do movimento intelectual francês dos Annales. Nesse estudo, Henri Berr reporta-se aos geógrafos alemães Carl Ritter e Friedrich Ratzel, já que Henri Berr, interessado na geografia histórica, influenciou fortemente Lucien Febvre a desenvolver um grande projeto - La terre et l'évolution bumaine, cujos resultados, em forma de livro, foram publicados em 1922 e 1925, neste caso em edição inglesa (BURKE, 1991). Repita-se, assim, que a presença da história e da cultura em Ideias para uma concepção geográfica da vida reflete a aproximação de Eidorfe Moreira com as matrizes epistemológicas que fundaram a relação entre história e geografia na origem do movimento dos Annales.

Muito embora haja escrito Kant como geógrafo em 1972, dez anos após publicar Ideias para uma concep̧cão geográfica da vida, parece evidente que a cosmovisão do filósofo e do geógrafo alemão já estava instalada no pensamento de Eidorfe Moreira. Não sem propósito, ainda que seguindo e segundo uma outra linha filosófica - o pensar a história pelos cânones do racionalismo das Luzes - não deixa de ser interessante lembrar que Kant escreveu, em 1784, sua Ideia de uma história universal, de um ponto de vista cosmopolita, aliás, mesmo ano em que Herder lançou o primeiro volume das suas Ideias para a filosofia da bistória bumana. O Iluminismo passava a trabalhar, filosoficamente falando, com um sentido novo de História, necessariamente associado à natureza, ao meio e ao sistemas físicos responsáveis pela manutenção da espécie humana.

É fundamental ressaltar que Eidorfe Moreira vai desenvolver em sua obra uma leitura que o aproxima de Jakob von Uexküll, autor de Ideias para uma concep̧̧ão biológica do mundo, cuja edição espanhola, de 1949, foi conhecida por Eidorfe Moreira. A problematização do mundo, dos animais e da vida por Uexküll foi marcante o bastante para projetar-se sobre a filosofia contemporânea, precisamente nos domínios da ontologia e da hermenêutica. Nesse sentido, a simetria entre as Ideias de Eidorfe Moreira e as de Jakob von Uexküll não será apenas pela semelhança entre os títulos dos ensaios, mas, como logo será visto, pelas visões de mundo que construíram, cada um à sua maneira.

Observe-se, no entanto, que dentre os títulos consultados e referidos por Eidorfe Moreira em Ideias para uma concep̧̧ão geográfica da vida, não figura qualquer 
das obras em que Lucien Febvre manifestou seus reconhecidos itinerários pela geografia histórica, sobretudo La terre et l'évolution bumaine. E para ficar na questão dos Annales, é de se notar que também neste caso não figura nas fontes buscadas por Eidorfe Moreira um outro grande lugar da geografia histórica, a saber: La Méditerranée et le monde méditerranéen à l'époque de Philippe II, de Fernand Braudel, cuja primeira edição data de 1949. De qualquer modo, parece evidente, a considerarse a estrutura narrativa de Ideias para uma concep̧̧ão geográfica da vida, que não foi desconhecido de Eidorfe Moreira (2012) a geografia histórica produzida ao abrigo dos Annales.

Esses, por assim dizer, silêncios na bibliografia referida por Eidorfe Moreira em Ideias para uma concepşão geográfica da vida, tratando-se dos títulos de Lucien Febvre e Fernand Braudel acima referidos, não enfraquecem o corpo analítico, a linha discursiva da obra. Afinal, outros títulos, oriundos também de outros contextos intelectuais, mas identificados com o corpus epistemológico das ciências históricas francesas, subsidiam o corpo teórico construído pelo ensaísta. Assim, e segundo uma relação mais próxima entre história e geografia cultural encontramse, dentre outros, em Ideias para uma concep̧̧ão geográfica da vida, os já referidos Lucien Febvre e Vidal de la Blache, e mais Hippolyte Taine, Humboldt, Pierre Deffontaines e Elisée Reclus. Que fique claro, entretanto, que a bibliografia trabalhada por Eidorfe Moreira cobre outros domínios, aliás, domínios que ele vai singrar em sua obra, como, por exemplo, "a função geográfica da mulher". Neste caso, não há como deixar de referir o ensaio Cultura feminina, de George Simmel.

Uma leitura mais rigorosa de Ideias para uma concepção geográfica da vida revela, nas palavras do seu autor (MOREIRA, 2012, p. 15), que a obra procurava trabalhar "uma Geografia sem espírito de sistema", distante e distanciada dos esquematismos e dos formalismos, e, por isso mesmo, aberta a domínios geralmente pouco trabalhados pelas formas clássicas, tradicionais, mesmo, do saber geográfico. Partindo desse pressuposto teórico, Eidorfe Moreira construirá uma narrativa heterodoxa, no tocante às questões que levantará, discutirá e analisará, até mesmo pelas aproximações que estabelecerá, por exemplo, entre geografia, filosofia e literatura. O autor, por esses caminhos, fundado em leituras relevantes que desenvolveu, acabará percorrendo, com originalidade, os caminhos da geografia cultural por ele conhecida e praticada.

O tratamento heterodoxo próprio da geografia cultural de Eidorfe Moreira, nas formas acima mencionadas, fica evidenciado pela natureza dos domínios por ele eleitos em sua abordagem filosófica da geografia cultural. Assim, em Ideias para uma concepção geográfica da vida o autor tanto trabalha a relação entre geografia 
e poesia como discute a cultura como paisagem. Neste caso, o da relação entre o homem e a paisagem, falará o ensaísta da cosmologia do amor, da função geográfica da mulher e da solidão do homem na paisagem, questões que só podem ser pensadas nos domínios da filosofia e da ontologia.

Os domínios percorridos por Eidorfe Moreira em Ideias para uma concepção geográfica da vida revelam um ensaísta para o qual a Geografia não se limita ao meio físico, antes integrando um sistema complexo que secularmente preocupa o homem: a natureza e seu sistema. E esse sistema, sustenta Eidorfe Moreira, a exemplo de Humboldt no século XIX, requer procedimentos variáveis de leitura e compreensão, inclusive aqueles de clara fundamentação estética (MOREIRA, 2012). Partindo-se desse pressuposto, é possível assegurar que a geografia cultural de Eidorfe Moreira projeta um pensamento que combina ciência e sensibilidade, pois trabalha com o homem que atua sobre o meio ambiente portando as suas grandes visões de mundo.

Observando-se a vida acadêmica brasileira como um todo, não deixa de causar espécie o fato de somente no início da década de 1990, em São Paulo e Rio de Janeiro, a geografia cultural passar a ser conhecida e praticada academicamente. Em 1993, a Universidade do Estado do Rio de Janeiro instituiu um Núcleo de Estudos e Pesquisas sobre Espaço e Cultura, investindo no espaço, nas manifestações da cultura popular e na religião. Ora, esses domínios e as problemáticas aos mesmos pertinentes já estão presentes em Ideias para uma concepção geográfica da vida, trabalho dado à estampa por Eidorfe Moreira, como visto, em 1960. Por isso mesmo, no trabalho do ensaísta figuram os nomes de escritores de várias nacionalidades, sobretudo franceses, que tradicionalmente tratavam questões pertinentes ao campo da geografia cultural.

Compreensível, assim, que os novos nomes da geografia cultural que atuaram no Brasil, como Marvin Mikesell, Denis Cosgrove e Paul Claval, por exemplo, retomassem pressupostos levantados por Carl Sauer, dilatando e problematizando os limites clássicos da geografia cultural, principalmente a francesa. Voltando a Eidorfe Moreira, as suas leituras fundadoras, como visto, estavam centradas sobre aqueles que, principalmente na França, Alemanha e Inglaterra, já discutiam, na primeira metade do século XX, o que seriam os fundamentos da moderna geografia cultural.

Finalizando, é possível sustentar que Ideias para uma concep̧cão geográfica da vida, em que pese, por assim dizer, a sua genética não acadêmica, revelou-se, dados os complexos culturais dominantes no Pará dos anos de 1960, um trabalho resultante de grande e pessoal investimento intelectual do seu autor. E mais: é uma obra que revela particular e intensa sensibilidade do seu autor no tocante às 
complexas relações entre o homem, a cultura e o meio ambiente. Ora, quando se olha o quadro das pesquisas e dos trabalhos da geografia cultural no Brasil dos anos de 1990, fica ainda mais realçada a precocidade e a originalidade da forma como Eidorfe Moreira trabalhou os compostos teóricos, metodológicos, mas, principalmente, históricos, da sua geografia cultural.

Os grandes quadros pintados nas passagens anteriores desta narrativa parecem deixar evidente que Eidorfe Moreira construiu um patrimônio intelectual que não ficou ancorado na geografia, na sua proclamada condição de geógrafo. Antes, as matrizes do conhecimento, nacional e internacional, visitadas por Eidorfe Moreira, suas leituras e suas aplicações teóricas e narrativas na obra que construiu, imprimiu a essa obra a marca de um saber fundado nas relações inter e transdisciplinares do conhecimento. Para melhor definir esta linha de argumentação, alguns títulos dados à estampa por Eidorfe Moreira podem ser melhor esquadrinhados, de tal forma que suas matrizes teóricas e metodológicas assegurem a procedência desse tipo de, por assim dizer, arguição. É o caso, como foi assinalado em passagem anterior, de Presença do mar na literatura brasileira, dado à estampa em 1962.

Este estudo será a seguir trabalhado na condição de um ensaio-chave do entendimento do seu autor acerca da natureza multifacetada do saber geográfico.

Trata-se de Presença do mar na literatura brasileira um ensaio de geografia cultural, dentre outros que o autor depois publicaria. Neste caso, Eidorfe Moreira vai trabalhar a literatura brasileira como também reflexiva da forte presença da paisagem na narrativa literária historicamente construída no Brasil, seja nos domínios da poesia, seja nos espaços da prosa. Como a paisagem em si resulta da relação entre natureza e cultura, seu corpus é discursivo, tanto no tocante à imagética quanto à narrativa escrita. Afinal, os próprios personagens da peripécia literária revelam-se como agentes ativos atuando na construção dos quadros da paisagem.

Nesse sentido, Eidorfe Moreira faz dele as palavras de Antonio Candido, em Formação da literatura brasileira, ao dizer que "O nosso romance tem fome de espaço e uma ânsia topográfica de apalpar todo o país” (MOREIRA, 1962, p.9). A paisagem, contudo, lembra Eidorfe Moreira, comparece à estrutura da narrativa literária como agente de seu enredo, e não como cenário, a exemplo do verificado em Guimarães Rosa. De qualquer modo, na construção da paisagem como enredo, em jogo está, assegure-se, o que Eidorfe Moreira identifica 
como a "unidade orgânica da Natureza, da Cultura e da História" (MOREIRA, 1962, p.10).

Ao escrever as "considerações gerais" de Presença do mar na literatura brasileira, Eidorfe Moreira fundou a sua leitura teórica em nomes que, à época, figuravam na vanguarda da história e da crítica literárias no Brasil. Além de Antonio Candido, Eidorfe Moreira recorreu também a Graça Aranha, Alceu Amoroso Lima, Viana Moog, Adonias Filho e Afrânio Coutinho. Valeu-se ele, também, do linguista e filósofo francês Albert Dauzat, na obra Le sentiment de la nature e son expression artistique, de 1914.

No corpus de Presença do mar na literatura brasileira como um todo, Eidorfe Moreira trabalha inicialmente o mar na poesia brasileira produzida no período colonial, para depois passar pelo romantismo, parnasianismo, simbolismo e modernismo. No tocante à prosa - objeto de nossa leitura - o estudo de Eidorfe Moreira privilegia a prosa de ficção e, também, memórias e ensaios - nestes casos, nos quadros da vida intelectual brasileira do século XIX e primeira metade do XX. Para distender um arco de tão amplo alcance investigativo, Eidorfe Moreira considera "a polivalência de sentido e de expressão que o mar tem na vida nacional, a soma de atividades, motivos e influências que lhe inspira, suscita ou promove em toda a extensão de nossa costa" (MOREIRA, 1962, p. 17). Tudo isso nos mostra a riqueza de motivações literárias que podemos encontrar nele.

Focando-se, no que diz respeito à prosa, o campo dos ensaios, Eidorfe Moreira faz referências a Victor Hugo, Pierre Loti e Jules Michelet, antes de começar a trabalhar com os ensaístas brasileiros. E o faz com Rui Barbosa em Cartas da Inglaterra, em sua "Lição do Extremo-Oriente", ao tratar da relação entre o mar e a defesa do Estado brasileiro, assim como da também relação com o poder naval e com a marcha de um país em direção ao progresso. A leitura do mar feita por Rui Barbosa reverbera de forma entusiástica em Eidorfe Moreira, para quem o autor de Cartas da Inglaterra, mesmo não sendo um profissional do mar, construiu "uma visão global e estrutural do nosso problema náutico, de acordo com as perspectivas e o espírito da época” (MOREIRA, 1962, p. 153).

Euclides da Cunha também foi visitado por Eidorfe Moreira em busca de registros sobre o mar feitos pelo autor de Os sertões, o que ele não encontraria certamente na epopeia euclidiana sobre Canudos, salvo de forma tangencial, já que a narrativa ambienta-se no cenário plantado em meio ao semiárido nordestino. No geral, tratando-se do Brasil, a busca de Eidorfe Moreira sobre o mar em Euclides da Cunha encontra referências em Contrastes e confrontos, quando o seu autor discute sobre os desafios brasileiros face a um litoral de grande extensão. E também em Os sertões, como acima lembrado, Euclides da Cunha faz 
algumas considerações sobre a Serra do Mar. Também em À margem da bistória e em Contrastes e confrontos, registros euclidianos sobre o mar aparecem no tocante à Rússia e sua relação ao Pacífico, e aos Estados Unidos, relativamente à costa oeste norte-americana.

Visitação também a Gilberto Freyre marca a preocupação ensaística de Eidorfe Moreira, tratando-se da representação do mar. Segundo o articulista, “a contribuição de Gilberto Freyre no que tange aos assuntos do mar é notável, sobretudo por ter realçado a significação e o papel do negro em relação ao mar. Ele projetou, por assim dizer, o negro na paisagem marinha". Em Sobrados e mucambos e ainda em Nordeste, este dado à estampa em 1927, Gilberto Freyre foca o negro "nas suas relações diretas com o mar" [...] "projetando, por assim dizer, o negro na paisagem marinha” (MOREIRA, 1962, p. 163). Assim, em Sobrados e mucambos, Eidorfe Moreira capta, por exemplo, uma dada leitura social do mar quando o seu autor registra que "as praias, nas proximidades dos muros dos sobrados do Rio de Janeiro, de Salvador, do Recife até os primeiros anos do século XIX eram lugares por onde não se podia passear, muito menos tomar banho salgado" (MOREIRA, 1962, p. 159).

A fim de definir claramente a relação do negro com o mar, Gilberto Freyre assinala, como aponta Eidorfe Moreira, que além do caboclo, o negro também foi canoeiro, jangadeiro e remeiro, atividades para as quais projetou comportamentos da sua cultura matricial. O espaço das pescas no nordeste litorâneo, assim, foi marcado, nas práticas que conheceu, também pela presença cultural do negro, e não apenas pelo do caboclo. Fica claro, dessa forma, que a preocupação de Eidorfe Moreira é mostrar que a presença do mar como gerador de práticas sociais já estava claramente construída na sociedade e na cultura brasileiras do período colonial.

Em outro domínio da ensaística brasileira, o dos estudos literários, Eidorfe Moreira trabalha com Gonzaga Duque, um esteta do mar. Em Graves e frivolos, por exemplo, o escritor trabalha a representação da praia como paisagem natural e como paisagem social, na forma como a imagem se instalou nas mentalidades do Brasil que abria o século XX. E no quadro dos grandes ensaístas brasileiros que incorporaram o mar como recurso literário, Eidorfe Moreira aponta Gilberto Amado. A inflexão estética, literária, do ensaísta sobre o mar, não o impede, contudo, de também centrar sua narrativa na história. Nesse sentido, em $A$ dança sobre o abismo, de 1952, que abriga uma incursão de Gilberto Amado sobre o Mediterrâneo, um mar que figura "não só como fonte e berço, mas também como imagem e síntese da Civilização [no] quadro histórico do progresso humano" (MOREIRA, 1962, p. 162). 
Ainda na ensaística brasileira da primeira metade do século XX, mas agora seguindo o eixo da geografia histórica - um dos polos dominantes de seus estudos - Eidorfe Moreira chega ao geógrafo Alberto Lamego em O homem e a restinga e $O$ homem e a Guanabara, dentre outros trabalhos. São estudos que se sustentam numa leitura da formação histórica das áreas litorâneas do Rio de Janeiro, daí o fato de o seu autor trabalhar "a colonização da costa fluminense [...] numa sequência que vai mostrado o seu lento desprendimento da gravitação e das influências oceânicas" (MOREIRA, 1962, p. 167). Fica evidente que Alberto Lamego empresta aos seus trabalhos um tratamento histórico-cultural da geografia, focando a relação entre meio e modo social das populações, daí os títulos de seus trabalhos anunciarem o homem como ponto primordial da leitura.

Das leituras finais realizadas por Eidorfe Moreira em Presença do mar na literatura brasileira, uma foi sobre o geógrafo Josué de Castro e seus Documentários do Nordeste, de 1957. Segundo Eidorfe Moreira, o texto de Josué de Castro, na forma de uma narrativa literária, enfatiza um processo que relaciona homem e meio, na forma, por exemplo, da "paisagem geo-social dos mangues pernambucanos, com sua vida anfíbia e miserável [...] todo esse mundo ambivalente entre terra e água se reflete com seu colorido típico e natural” (MOREIRA, 1962, p. 169-170).

Essa abordagem de uma geografia histórico-cultural, Josué de Castro igualmente manifesta em Um ensaio de geografia humana: a cidade de Recife, de 1957. Aqui, a cidade, em dupla face, volta-se tanto para o mar das pescas e das jangadas quanto para o mar das canas, quer para o litoral pesqueiro, quer para a terra canavieira. Trata-se, no caso, da forma como, historicamente falando, o Recife se relacionou com os domínios históricos da sua construção social. Aliás, quanto às jangadas como representação sociocultural, e de forma a salientar o tratamento cultural da geografia, domínio por excelência da sua preocupação epistemológica, Eidorfe Moreira busca a antropologia de Câmara Cascudo em seu estudo $A$ jangada, publicado em 1957. Nesse sentido, sustenta o articulista que "quem diz jangada diz naturalmente uma tipologia humana e geográfica, um tipo de embarcação e um processo haliêutico" (MOREIRA, 1962, p. 173). Conclui Eidorfe Moreira sustentando que "a parte final do trabalho de Câmara Cascudo é uma antologia da jangada, o reflexo das suas influências em nossas letras" (MOREIRA, 1962, p. 177).

Em Presença do mar na literatura brasileira, Eidorfe Moreira redefiniu e melhor alargou preocupações já manifestadas em Ideias para uma concep̧ão geográfica da vida, de 1960. O investimento do articulista numa geografia histórica e culturalmente trabalhada produziu, assim, os seus frutos, na medida em que o fio condutor de sua análise levou-o ao encontro das dimensões sócio-históricas da geografia. 
Dispensa enfatizar que em outros trabalhos que publicaria posteriormente, no correr da década de 1970, redefiniria ele os paradigmas dessa geografia tomada também como linguagem e representação cultural.

Como o que está em exame é a condição do trabalho intelectual de Eidorfe Moreira, objeto de relações interdisciplinares e transdisciplinares, é significativo constatar, mesmo que em linhas gerais, de que forma o ensaísta se voltou para Antônio Vieira em Os sermões que Vieira pregou no Pará, um opúsculo de 23 páginas dado à estampa pela Imprensa Universitária da UFPA, em 1970 (COELHO. Afinal, o grande pregador é figura-chave na estrutura narrativa e discursiva do barroco luso-brasileiro, um Vieira que Eidorfe Moreira certamente assimilou como um pensador que construía um pensamento que transitava pela teologia, pela filosofia, pela história, pela retórica; um Vieira, a seu tempo, igualmente um intelectual que produziu um saber transdisciplinar. Em seu estudo, Eidorfe Moreira chama a si os quatro sermões que Vieira recitou na igreja matriz de Belém entre 1656 e 1658, aquando da passagem do grande pregador pelo Pará, na época, abrigando importantes missões jesuíticas fincadas no interior da Amazônia. Em seu breve relato sobre o quê em Belém produziu o sermonário vieiriano, Eidorfe Moreira trabalhou com uma bibliografia polimórfica.

De um lado, reuniu os títulos clássicos de João Lúcio de Azevedo, a saber: História de Antônio Vieira, com seus dois tomos publicados em Lisboa, entre 1918 e 1921, e Os jesuítas no Grão-Pará, dado à estampa em Coimbra, em 1930. No tocante ao sermonário de Vieira como um todo, Eidorfe Moreira valeu-se de um outro clássico, Les sermons de Vieira; étude du style, de Raimond Cantel, publicado em Paris, em 1959. E do próprio Vieira o estudioso paraense consultou os Sermões, em 15 volumes, publicados em Lisboa, entre 1907 e 1909.

Outros monumentos bibliográficos sustentam a leitura de Eidorfe Moreira sobre o quadro histórico em cujo interior está presente a Companhia de Jesus no Grão-Pará de então. É o caso, por exemplo, da História da Companbia de Jesus na extinta provincia do Maranhão e Pará, estampada por Cândido Mendes de Almeida em suas Memórias para a história do extinto Estado do Maranbão, em dois tomos saídos no Rio de Janeiro, em 1860 e 1874 . Veja-se, ainda, que não escapou e nem poderia escapar a Eidorfe Moreira a História da Companbia de Jesus no Brasil, de Serafim Leite, cujos dez tomos foram dados à estampa entre 1938 e 1950, em Lisboa e no Rio de Janeiro. 
A bibliografia consultada por Eidorfe Moreira à época, para escrever Os sermões que Vieira pregou no Pará, respondia, em parte, pelo então estado das questões acerca do Vieira histórico (COELHO, 2010, p. 22). E certamente demarcava os limites do campo de leitura privilegiado por Eidorfe Moreira acerca das representações da práxis vieiriana no que era a Belém de uma iniciada segunda metade do século XVII. Isso explica a ausência de títulos de autores que alargaram a linha de leitura da obra de Vieira, a exemplo de outros títulos do já citado Raimond Cantel, assim como de outros autores que se debruçaram sobre Vieira, a exemplo de Ernani Cidade.

É verdade que na Belém do final dos anos de 1960, quando Eidorfe Moreira certamente pensou em trabalhar os sermões que Vieira proferiu em Belém, era difícil ter em mãos, por exemplo, títulos saídos quer no Brasil, quer na Europa, sobre o sujeito histórico Antônio Vieira. Tal contingência, de qualquer modo, deve ser relativizada, posto que a biblioteca particular de Eidorfe Moreira, como ele mesmo revelou, era de uma riqueza invulgar. Assim, os títulos que elegeu para contingenciar, histórica e estilisticamente, Os sermões que Vieira pregou no Pará, iam ao encontro, segundo o seu entendimento, da narrativa que elaborou acerca da presença de Vieira na seiscentista Belém do Grão-Pará (COELHO, 2009, p. 33).

E se lembrarmos que somente a partir dos anos de 1990 passaram a surgir, por exemplo, em Portugal e no Brasil, novos estudos a alargar o horizonte de leitura tanto do Vieira histórico da Companhia de Jesus quanto o do discurso teológico inaciano, a bibliografia consultada por Eidorfe Moreira respondia, à altura em que escreveu o seu opúsculo, aos imperativos epistemológicos do seu estudo. Eidorfe Moreira foi, a seu tempo, um intelectual à frente do seu próprio tempo.

\section{REFERÊNCIAS}

AZEVEDO, J. L. Os jesuítas no Grão-Pará. 2.ed. Belém: Secult, 1999.

BAENA, A. Compêndio das eras da Província do Pará. Belém: Universidade Federal do Pará, 1969.

BURKE, P. A escola dos Annales. 1929-1989; a Revolução Francesa da historiografia. São Paulo: Unesp, 1991.

CHAMBOULEYRON, R. Missionários, índios, capitães e moradores: relações e conflitos na Amazônia seiscentista. In: FORLINE, L. C. et al. Amazônia: além dos 500 anos. Belém: Museu Paraense Emílio Goeldi, 2006. 
CHAVES, M. A. Nota biográfica. In: MOREIRA, Eidorfe. Obras reunidas. Organização de Maria Annunciada Chaves. Belém: Conselho Estadual de Cultura do Pará; Seduc; Cejup, 1989, v. 1. p. 17-24.

COELHO, G. M. O visionário da Amazônia. Revista de História da Biblioteca Nacional, Rio de Janeiro, n. 63, p. 22-24, 2010.

O espelho da natureza: poder, escrita e imaginação na revelação do Brasil. Belém: Paka-Tatu, 2009.

MOREIRA, E. Ideias para uma concepção geográfica da vida. Organização de Maria Stella Faciola Pessôa Guimarães. Belém: Semec, 2012. 2. ed.

Obras reunidas. Organização de Maria Annunciada Chaves. Belém: Conselho Estadual de Cultura; Seduc; Cejup, 1989. 8 v.

Os sermões que Vieira pregou no Pará. Belém: Universidade Federal do Pará, 1970.

Presença do mar na literatura brasileira. Belém: H. Barra, 1962.

. Amazônia: o conceito e a paisagem. Rio de Janeiro: Agência da SPVEA, 1960.

. Sertão: a palavra e a imagem. Belém: H. Barra, 1959.

NUNES, B. Nota crítica. In: MOREIRA, Eidorfe. Obras reunidas. Organização de Maria Annunciada Chaves. Belém: Conselho Estadual de Cultura; Seduc; Cejup, 1989, v. 1. p. 25-28.

PÉCORA, A. Teatro do Sacramento. São Paulo: Iedusp, 1994.

VIEIRA, A. Sermões. Organização de Alcir Pécora. São Paulo: Hedra, 20002001. $2 \mathrm{v}$. 